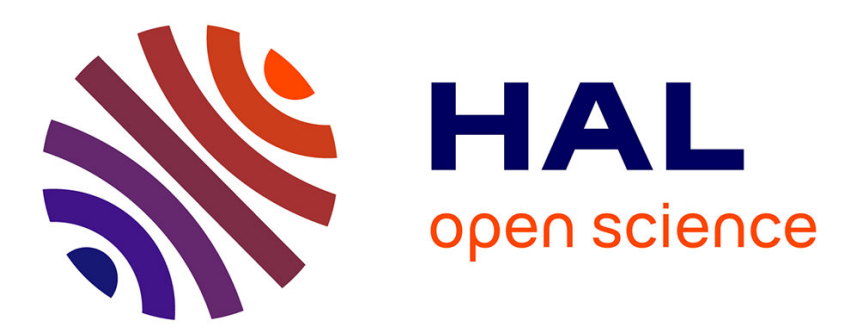

\title{
Air-coupled guided waves combined with thermography for monitoring fatigue in biaxially loaded composite tubes
}

\author{
M. Rheinfurth, F. Schmidt, D. Döring, I. Solodov, G. Busse, P. Horst
}

\section{- To cite this version:}

M. Rheinfurth, F. Schmidt, D. Döring, I. Solodov, G. Busse, et al.. Air-coupled guided waves combined with thermography for monitoring fatigue in biaxially loaded composite tubes. Composites Science and Technology, 2011, 71 (5), pp.600. 10.1016/j.compscitech.2010.12.012 . hal-00730305

\section{HAL Id: hal-00730305 https://hal.science/hal-00730305}

Submitted on 9 Sep 2012

HAL is a multi-disciplinary open access archive for the deposit and dissemination of scientific research documents, whether they are published or not. The documents may come from teaching and research institutions in France or abroad, or from public or private research centers.
L'archive ouverte pluridisciplinaire HAL, est destinée au dépôt et à la diffusion de documents scientifiques de niveau recherche, publiés ou non, émanant des établissements d'enseignement et de recherche français ou étrangers, des laboratoires publics ou privés. 


\section{Accepted Manuscript}

Review

Air-coupled guided waves combined with thermography for monitoring fatigue in biaxially loaded composite tubes

M. Rheinfurth, F. Schmidt, D. Döring, I. Solodov, G. Busse, P. Horst

PII:

S0266-3538(10)00480-X

DOI:

10.1016/j.compscitech.2010.12.012

Reference:

CSTE 4877

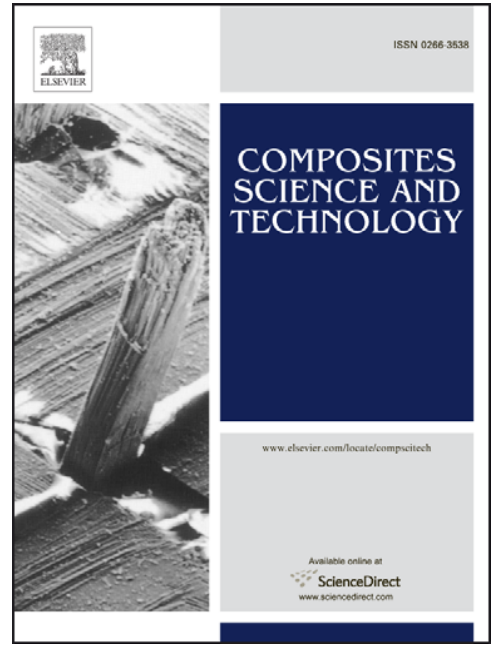

To appear in:

Composites Science and Technology

Received Date:

2 June 2010

Revised Date:

30 November 2010

Accepted Date:

9 December 2010

Please cite this article as: Rheinfurth, M., Schmidt, F., Döring, D., Solodov, I., Busse, G., Horst, P., Air-coupled guided waves combined with thermography for monitoring fatigue in biaxially loaded composite tubes, Composites Science and Technology (2010), doi: 10.1016/j.compscitech.2010.12.012

This is a PDF file of an unedited manuscript that has been accepted for publication. As a service to our customers we are providing this early version of the manuscript. The manuscript will undergo copyediting, typesetting, and review of the resulting proof before it is published in its final form. Please note that during the production process errors may be discovered which could affect the content, and all legal disclaimers that apply to the journal pertain. 


\title{
Air-coupled guided waves combined with thermography for monitoring fatigue in biaxially loaded composite tubes
}

\author{
M. Rheinfurth ${ }^{1, *}$, F. Schmidt ${ }^{2}$, D. Döring ${ }^{1}$, I. Solodov ${ }^{1}$, G. Busse ${ }^{1}$, and P. Horst ${ }^{2}$ \\ ${ }^{1}$ Institute for Polymer Technology, Department of Nondestructive Testing (IKT-ZfP), \\ Stuttgart University, Pfaffenwaldring 32, D-70569 Stuttgart, Germany \\ ${ }^{2}$ Institute of Aircraft Design and Leightweight Structures (IFL), Braunschweig Technical \\ University, Hermann-Blenk-Straße 35, D-38108 Braunschweig, Germany \\ *Corresponding author: Tel.: 0049-711-685-62669, Fax: 0049-711-685-64635, \\ eMail: martin.rheinfurth@ikt.uni-stuttgart.de
}

\begin{abstract}
Non-destructive methodologies for remote monitoring of fatigue induced by mechanical load in fibre reinforced plastics are presented. Hollow cylinders (glass fibre winding) were stepwise biaxially fatigued and measured in single-sided access configurations. Based on conversion of air-coupled ultrasound to guided waves, it is shown that accumulated fatigue damage is accompanied by decrease in phase velocity and increase in attenuation. The change in wave velocity caused by fatigue is shown to correlate closely with measurements of stiffness degradation of the composite. The attenuation of guided waves is affected by crack density which is visually traceable in the transparent composite. Monitoring of cyclic loading of the specimens by thermal imaging and a high-speed camera revealed that the initiation of final failure in the specimens coincides with spots of increased temperature. Air-coupled guided wave area scans allow for observing the development of these areas and other local damage in the composite.
\end{abstract}

Keywords: A. Polymer-matrix composites, B. Fatigue, D. Non-destructive testing, D. Ultrasonic, D. Air-coupled guided waves 


\section{Introduction}

The global demand for polymer-matrix composites in various industries has been rising enormously due to their high specific strength and stiffness. The performance of fibre reinforced plastic (FRP) is affected by material degradation resulting from mechanical loads. Fatigue damage is particularly important in applications (aircraft, wind energy) where the components encounter many loading cycles during their lifetime.

Mechanically induced fatigue in FRP reveals several damage mechanisms (matrix cracking, delamination and fibre fracture), which correlate with stiffness degradation [1, 2]. Fatigue damage in composites can be divided into three stages. During the initial stage I, matrix cracks develop in plies loaded orthogonally to the fibre orientation, which leads to a rapid decrease in stiffness. Stage II is characterised by a slight quasilinear decrease in stiffness and the development of a critical damage stage (saturation of matrix cracks) with initial local delaminations caused by transverse cracks. The last stage (III) includes consolidation of local delamination and fibre cracking, which results in catastrophic failure. The hollow cylinders investigated in this study enable cyclic loading with arbitrary load ratios between tension/compression and torsion. This geometry without free edges is adequate to simulate fatigue damage formation in commonly employed FRP components.

For non-destructive detection of fatigue-induced defects, innovative methodologies are needed to secure functionality and avoid unnecessary replacement of components. Several techniques (acoustic emission, electric resistivity, optical fibres etc.) have been proposed for detection and characterization of fatigue damage in FRP caused by cyclic loading. Each of the techniques comes along with its drawbacks such as expensive 
sensors for structural health monitoring using smart structures or challenging application in industrial environment.

The correlation between the area of highest temperature (hot spot) during cyclic loading and the location of final failure was revealed using thermography [3]. The development of hot spots indicates a material state close to failure. Thermography was applied to the study presented to complement the investigations.

Conventional ultrasonic technique for probing material stiffness and its degradation involves direct measurements of bulk wave velocities [4]. However, this methodology requires an immersion bath and two-sided access, which impedes in-situ application. Furthermore, the data obtained in this transmission mode are often not applicable to fatigue monitoring in strongly heterogeneous composite materials.

Guided waves in tubes behave similarly to Lamb waves for certain ratios between wall thickness, radius and wavelength [5]. Lamb waves are two dimensional guided waves travelling in plate-like structures. They offer a convenient method for recovering inplane elastic properties $[6,7]$. Contact Lamb wave setups were found to be applicable to monitoring stiffness degradation in FRP induced by thermal and mechanical ageing [810]. It was shown that the attenuation is sensitive to cracking induced by fatigue for a circumferential wave propagating in hollow FRP cylinders [11].

Air-coupled ultrasound (ACU) has been increasingly used for inspection of plate-like components in recent years due to its advantage of being a non-contact and nonimmersion methodology [12]. The conventional normal transmission mode has been modified to provide mode conversion of air-coupled ultrasound to Lamb waves for 
remote non-destructive evaluation in a single-sided access configuration [13]. A similar technique was recently applied to measuring phase velocity and attenuation for testing moisture content and micro cracking in carbon fibre reinforced plastic [14]. Air-coupled Lamb wave imaging was also used to detect local defects like delaminations in composites [15].

In this paper, the ACU mode conversion is applied to the study of guided wave velocity and attenuation in cyclic loaded composite cylinders (tube winding). It is shown that these parameters correlate with stiffness degradation and crack density. Local modification/damage in the composite observed with ACU is compared to thermal imaging and visual inspection. It is shown that theses techniques allow for monitoring of fatigue in FRP induced by mechanical loads.

\section{Material and specimens}

The specimens used during these investigations were nominally defect-free wound tube specimens made of E-Glass-fibre rovings (Owens Corning, type OC111A). They were produced by a winding machine, which enables manufacturing of arbitrary lay-ups. As in previous research [11], the specimens consist of 8 layers with a symmetric lay-up of $\left[0^{\circ} / 45^{\circ} / 90^{\circ} /-45^{\circ}\right]_{S}$. For this work, the relative mass fractions of the layers were $49 \%$

$\left(0^{\circ}\right), 23 \%\left(45^{\circ}\right), 5 \%\left(90^{\circ}\right)$, and $23 \%\left(-45^{\circ}\right)$. Together with a common resin/hardenercombination (RIM135/RIMH137) the wound tube specimens were manufactured by using resin transfer moulding (RTM) with the inner and outer $0^{\circ}$-angled plies being parallel to the axial direction of the tube specimens. The mechanical properties of the materials are presented in Table 1. 
The tested specimens were tubes of $46 \mathrm{~mm}$ diameter and $330 \mathrm{~mm}$ length with approximately $2.0 \mathrm{~mm}$ thickness and a fibre volume fraction of about $50 \%$. In further production steps, both ends of the tube specimens were reinforced by glas-FRPdoublers of $70 \mathrm{~mm}$ length and bonded steel inserts which prevented failure caused by the fixing pressure of the testing machine.

The advantages of the wound tube specimens are the possibility to apply biaxial loads (combination of tension/compression and torsion) with arbitrary load ratios and to prevent the so-called free-edge effect which occurs under fatigue loading using flat specimens. Due to different fibre orientations in the plies, the selected lay-up promises high intra- and interlaminar stresses throughout cyclic loading resulting in development of matrix cracks.

\section{Experimental set-up and analysis}

The experiments were arranged to allow for inducing fatigue damage accompanied by non-destructive testing. The fatigue experiments were accomplished with a servohydraulic tension-torsion machine. The circular clamping of this testing machine enabled testing of the described tube specimens. All fatigue tests were performed in a force-controlled manner with $\mathrm{R}=-1$ and a frequency of $3 \mathrm{~Hz}$. $\mathrm{R}$ describes the ratio between the minimum and maximum stress $\sigma$ during one fatigue cycle, as follows:

$$
\mathrm{R}=\frac{\sigma_{\min }}{\sigma_{\max }}
$$

Furthermore, different biaxial load ratios were investigated, whereas the biaxiality ratio (parameter $\beta$ ) is defined as:

$$
\beta=\arctan (\tau / \sigma)
$$


Thereby, the angle between shear stress $\tau$ and tensile/compressive stress $\sigma$ indicates the different biaxial load cases. Four different load cases were chosen for experiments, whereas the biaxiality ranges from pure shear $\left(\beta=90^{\circ}\right)$ to pure tension/compression $(\beta$ $=0^{\circ}$ ). The other load cases are $\beta=30^{\circ}$ (combination of tension/compression and torsion with the tension/compression part being dominant) and $\beta=60^{\circ}$ (also combination of tension/compression and torsion with a predominant shear part). The loading directions and magnitudes are listed in Table 2.

The fatigue tests were divided into three repetitive steps:

1. Characterization step: In order to monitor the material stiffness, quasi-static tests were conducted with force-controlled ramps (pure discrete tension/compression force and positive/negative torsion moments). These loads were considerably smaller than the applied fatigue loads and chosen in such a way that the load was adequate for calculating the Young's and shear modulus.

2. Fatigue damage step: Cyclic loads (sinus wave form) with constant amplitudes and different biaxial load ratios were performed to introduce fatigue damages like matrix cracking, delaminations and fibre failure. During each fatigue damage step, thermographic monitoring was applied for locating the final failure in an early stage of fatigue life. Furthermore, a photo camera was used for observing the qualitative development of cracks and for recording the final fatigue fracture (high-speed-mode with 60 pictures per second).

3. ACU measurement and crack monitoring: In order to observe the damage mechanisms the fatigue test was stopped after several fatigue steps and the specimen was taken out of the testing machine. The ACU measurements (Section 4) were conducted in this phase of the fatigue test. Online thermal imaging often indicated imminent failure so that the fatigue step was stopped to achieve ACU 
measurements just before failure. The matrix cracks, which are the first type of damage occurring, were studied using an optical microscope due to the transparency (similar refraction index of glass fibre and resin) of the specimen. Photos of several different areas of the tube were taken and used for crack counting. The cracks observed were aligned along the fibre direction of each ply. Differentiating the cracks by their orientation angle leads to the number in each layer which was referred to the size of the digital picture to calculate the crack densities presented in this work.

For exact measurements with the thermography camera, a constant ambient temperature of $20^{\circ} \mathrm{C}$ is required. This was assured by a cooling chamber installed between the grips of the testing machine. External fatigue loads (during fatigue damage step) cause an increase of the surface temperature measured by thermography. During the characterization step the tube specimen was cooled down to the initial constant temperature of $20^{\circ} \mathrm{C}$. Therefore, the maximum surface temperature was $30^{\circ} \mathrm{C}$ (except for the occurring hot spot), which prevented potential thermal damage of the matrix during fatigue life.

\section{Methodology of air-coupled guided waves}

Guided waves spanning over the whole tube circumference and propagating in axial direction take the form of longitudinal, flexural, and torsional modes. In the experiments conducted, however, the wave propagates only in a narrow segment of the tube wall. Theoretical studies and simulations have shown that for a slightly curved wall (wavelength and thickness $<<$ radius), the longitudinal/flexural modes can be regarded to be sufficiently like Lamb modes in a plate-like structure. 
The mode conversion of ACU to Lamb (plate) waves is based on resonance excitation in oblique incidence satisfying the relation [5]:

$$
\theta=\arcsin \left(V_{a} / V_{p}\right),
$$

where $\theta$ is the angle of incidence, $V_{a}$ the phase velocity of ultrasound in air and $V_{p}$ the phase velocity of the plate wave mode. Equation (3) also defines the re-radiation angles of ultrasound in air by the propagating wave from both surfaces of the specimen, which enables to use a single-sided configuration (Fig. 1). To prevent interference with ultrasound reflected by the specimen surface a sound absorbing shield between the transducers was installed. Without knowing the plate wave velocity, the adjustment of the incident angle $\theta$ can be performed by searching for the maximum output signal obtainable. The efficiency of excitation/reception also depends on the plate wave mode; the maximum coupling between ACU and plate wave is provided for the zero-order antisymmetric mode $\left(a_{0}\right)$ with predominately out-of-plane polarization [15].

Despite the curvature of the specimen, good coupling between ACU and the $a_{0}$-mode ( $a_{0}$-like) parallel to the cylinder axis was observed. In the experiments, commercial 207 $\mathrm{kHz}$ air-coupled transducers with a circular aperture of $8 \mathrm{~mm}$ diameter were used. The distance between the transducers and the specimen surface was set to $15 \mathrm{~mm}$. For small values of $\theta\left(8.5^{\circ}\right)$, the size of excitation area was between one and two wavelengths of the $a_{0}$-mode, so that excitation/detection was not sensitive to minor variation $\left( \pm 2^{\circ}\right)$ of angles of incidence. That enabled to use the same settings for a variety of specimens of slightly different thickness and stiffness, which makes the method applicable in-situ.

To measure the wave velocity and attenuation, the receiver is moved stepwise along the propagation path of the wave. The Discrete Fourier Transformation (DFT) of the output signal is used to obtain both amplitude and phase at each step (1 mm). These values as 
function of the distance between the transducers are used to calculate phase velocity and attenuation.

The relation between velocity of the $\mathrm{a}_{0}$-mode $V_{a 0}$ and the thickness of a plate $d$ can be obtained from the following approximation [5]:

$$
V_{a 0} \approx c \sqrt{\pi \cdot f \cdot d}
$$

where $c$ is the factor characterising the material properties and $f$ is the frequency.

Equation (4) is derived for flexural waves where the $\mathrm{a}_{0}$-mode wave propagates in an acoustically thin plate (thickness $\ll$ wavelength). Besides isotropic materials, it is also applicable to waves in symmetry directions of anisotropic materials [16]. In this study, the relation is assumed to be an approach for monitoring of small variations in wall thickness of the layered media investigated.

The wave velocities measured were assured by comparing them with predicted data using the commercial software Disperse [17]. The stiffness matrix of the layers was calculated using the elastic properties of fibre and matrix (Table 1). The velocities calculated do not take into account the curvature of the tube since iteration of the dispersion curves is currently not available for this type of problem.

The major contribution to the attenuation generally comes from damping (scattering and viscoelastic effects) and diffraction losses due to a finite aperture of the wave beam. Measurements have revealed that the beam divergence is small for the propagation in the heterogeneous material studied. The energy is trapped in certain propagation paths in axial direction because the structure of rather large rovings in comparison to the laminate thickness and wavelength acts as a waveguide which reduces the diffraction losses. Averaging of measurements over the whole tube circumference is considered to 
give a reasonable trend of dissipation throughout the fatigue process. The curvature and the lay-up of the composite induce anisotropy which affects the beam divergence. In the vicinity of the axial direction, the velocity variation with the azimuth angle $\xi$ can be described by the parabolic approximation [18]

$$
V(\xi) \approx V\left(0^{\circ}\right) \cdot\left(1-\gamma \xi^{2}\right)
$$

where $\gamma$ is the anisotropy parameter. The theory of diffraction [18] shows that due to the anisotropy the Fresnel distance becomes

$$
F_{A}=\frac{F_{I}}{1-2 \gamma}
$$

where $F_{A}$ and $F_{I}$ are the Fresnel distances with and without anisotropy, respectively.

Disperse and an analytical approach from Victorov [5] reveal for axial and circumferential wave propagation, respectively that the velocity variation due to curvature is below $0.5 \%$. The effect on diffraction can be neglected for the weak curvature $(|\gamma|<<1)$. The intrinsic material anisotropy (higher reinforcement in axial direction, $\gamma>0$ ) reduces the diffraction losses. The amplitude variation of a quasi-plane wave can therefore be approximated by an exponential decay:

$$
A(x)=A_{0} e^{-\alpha x},
$$

where $\alpha$ is the factor of attenuation caused by viscoelasticity and scattering, $A_{0}$ is the initial amplitude at the starting point of the receiver, and $x$ is the propagation distance.

The velocity and attenuation of the $\mathrm{a}_{0}$-like mode measured parallel to the axis of the tubes were used for the evaluation of fatigue state. The measurements were performed along 20 parallel lines positioned equally around each tube $\left(18^{\circ} / 7 \mathrm{~mm}\right)$. The data obtained are an average over $70 \mathrm{~mm}$ length due to the measurement method (Fig. 1). 
Precise alignment of the receiver path parallel to the specimen surface is crucial for measurement of velocity. To compare successive line scans, the positioning in circumferential and axial direction needs to be kept precisely. For this purpose a scanning device was developed which rotates and translates the tube (Fig. 2). Easy replacement of the specimens while maintaining the alignment was realized by a spring support. Validation of reproducibility was secured by repeatedly measuring an intact specimen throughout the entire series of fatigue measurements resulting in the standard deviation discussed in Section 5.

The same apparatus was employed for scanning and imaging the surface of the tube using two additional transducers at a constant distance of $20 \mathrm{~mm}$ (Fig. 2). A small step size ( $1 \mathrm{~mm}$ along the axis and $1.8^{\circ} / 0.7 \mathrm{~mm}$ around the circumference) in comparison to the transducer aperture was chosen. In combination with a Gaussian low-pass image filter, this reduces noise without any loss in image quality. To monitor modification/damage in the composite, scans before load application and after each fatigue step were processed and compared. The processing included subtracting the grey values of a former scan (A) from a following scan (B). The difference is then normalised by the averaged amplitude of the subtrahend (former scan):

$$
D=\frac{B-A}{f(A)}, \quad f(A)=\frac{1}{N} \sum_{i, j} a_{i j}
$$

where $\mathrm{D}$ is the deviation matrix (deviation image) and $\mathrm{N}$ is the number of matrix elements $a_{i j}$. The deviation image (in percent) allows for quantitative monitoring of the variation in amplitude of the area scans.

\section{Results}


Throughout cyclic loading, Young's modulus, shear modulus, crack density and the $\mathrm{a}_{0^{-}}$ mode-like wave velocity/attenuation were measured for the five stepwise fatigued specimens. The measurements were complemented by online thermal imaging, highspeed video recording and air-coupled guided wave area scans.

\subsection{Stiffness degradation and guided wave velocity}

The composite tubes exhibit stiffness degradation (up to 12\%, Tube-0: $24 \%$ ) throughout cyclic loading, as shown for the Young's modulus (measured in axial tension) in Fig. 3 (left). The shear modulus (measured by torsion of the tube) develops in a similar manner but decreases by up to $29 \%$. Within the first $15 \%$ of the lifespan, fibre matrix debonding and matrix cracking within the rovings develop (Fig. 3, right) leading to a high degradation in stiffness. After crack density saturation most tubes exhibit only a minor further decline in stiffness till failure. However, the uniaxially loaded specimen Tube- 0 shows a significantly steeper decrease in tensile modulus starting at $50 \%$ of its lifespan caused by fibre cracking in the extensively delaminated inner $0^{\circ}$ rovings.

The decrease in $\mathrm{a}_{0}$-mode wave velocity caused by the stiffness degradation is illustrated for the biaxially loaded specimen Tube-60a in Fig. 4. An average velocity $1230 \mathrm{~m} / \mathrm{s}$ was measured for the intact specimen. The absolute velocity values calculated by Disperse were lower than the measured values by $4 \%$, which could be partly explained by the neglected curvature of the specimen. For wave velocities around $1200 \mathrm{~m} / \mathrm{s}$, a deviation from parallelism between the receiver path and the specimen surface of $0.1^{\circ}$ results in an inaccuracy of $0.6 \%$ in velocity. A constant deviation of about $0.3^{\circ}$ is accepted in the experiments leading to an error in velocity of $2 \%$. However, the variation in velocity caused by fatigue is not affected by this systematic (but constant) deviation of the absolute values. 
Before and throughout cyclic loading, the inhomogeneity of the tube results in velocity variations of up to $100 \mathrm{~m} / \mathrm{s}$ along different propagation paths of the wave (Fig. 4, left). The velocity along each line of the measurement decreases steadily by between 50 and $120 \mathrm{~m} / \mathrm{s}$ (standard deviation below $3 \mathrm{~m} / \mathrm{s}$ ) during fatigue. The first measurement was performed before cyclic loading and the last after 33850 cycles, which was $99.6 \%$ of the lifespan. Only on the line at $54^{\circ}$ a rise in velocity was observed, which is attributed to a variation of the dominating propagation path of the $\mathrm{a}_{0}$-mode due to fatigue induced changes in the composite (Fig. 4, right).

For the 5 stepwise fatigued specimens, the velocity (average along 20 lines) of the $\mathrm{a}_{0^{-}}$ mode decreases rapidly within the first $15 \%$ of the lifespan, as shown in Fig. 5. This corresponds to the measurements of the Young's modulus shown in Fig. 3 (left). The gradual decline in the wave velocity till final failure appeared to be large compared to moderate tensile modulus degradation. Hence, stiffness matrix components, which are crucial for the plate wave velocity but not measurable with the servo-hydraulic testing machine, still significantly decrease at this stage of fatigue. For instance, merging cracks develop delaminations between the plies causing degradation of the out-of-plane tensile modulus.

The uniaxially loaded specimen (Tube-0) exhibits a different mode of failure, which can be seen by the steep decline in velocity during the second half of its lifespan (Fig. 5). The specimen suffers from large delaminations of the inner $0^{\circ}$ layer developing after $50 \%$ of the lifespan. In the delaminated areas the flexural wave propagates only in the outer laminate resulting in a drop in velocity of about $14 \%$. According to Equation (4), the depth of the delamination $d_{d}$ can be estimated as: 


$$
d_{d} \approx d\left(\frac{V_{a d}}{V_{a 0}}\right)^{2}
$$

where $V_{a d}$ is the velocity in the area of delamination. The calculated depth $(1.5 \mathrm{~mm})$ from the velocity coincides with the delamination depth between the inner $45^{\circ}$ and the inner $0^{\circ}$ ply.

\subsection{Crack density and guided wave attenuation}

Within the first $15 \%$ of lifespan the crack density reaches almost saturation in all layers, as illustrated in Fig. 3 (right) for Tube-60a. The different crack densities for the layers are caused by the load directions differing in each ply. The cracks develop mainly due to tension load orthogonal to the fibre direction. A similar development was found in all specimens except for the specimen Tube- 0 , where the $45^{\circ}$ and $-45^{\circ}$ layer exhibited approximately the same crack density while the overall crack density was lower.

The variation in $\mathrm{a}_{0}$-mode attenuation due to cyclic loading appears to be steady but not constantly increasing for every line of measurement, as shown in Fig. 6 (left) for one quarter of the specimen Tube-60a. For most measurements, an increase in attenuation between 0 and $20 \mathrm{~m}^{-1}$ was observed (standard deviation of repeated measurements was

$3 \mathrm{~m}^{-1}$ ). In some cases, however, even "negative attenuation" (increase in amplitude) and values of $\alpha$ up to $80 \mathrm{~m}^{-1}$ of "local" attenuation were measured. We believe that energy redistribution due to wave guiding effects causes these extreme values. Heterogeneous change in the FRP induced by fatigue also affects wave guiding and the attenuation. Hence, a single attenuation measurement is not suited to monitoring fatigue, as shown in Fig 6 (left) at $54^{\circ}$. The higher attenuation around $30 \%$ of the life span corresponds to the abnormal velocity rise along this line (Fig. 4, right, $54^{\circ}$ ). In this particular composite, changes in wave guiding for a single measurement can even affect the 
averaged and normalised attenuation measurements (Fig. 6, right). However, the incline in attenuation corresponds to the increase in crack density (Fig. 3, right). In particular, the small increase in attenuation for specimen Tube- 0 agrees with the lower crack density observed.

\subsection{Detection of delaminations}

The area scan $\left(360^{\circ}\right.$ corresponds to the circumference of $\left.139 \mathrm{~mm}\right)$ of the intact specimen (Tube-0) reveals considerable heterogeneity of the FRP (Fig. 7, a). The stripe pattern caused by wave guiding in axial direction reveals an amplitude deviation from the average of up to $\pm 50 \%$. The pattern observed is related to the alignment of the peripheral $0^{\circ}$ fibres. However, the number of stripes differs from the one of the $0^{\circ}$ rovings. Hence, the combination of a couple/few rovings at the inner and outer surface of the tube is considered to result in guiding of the $\mathrm{a}_{0}$-mode wave. This effect complicates the visualisation of defects since the inhomogeneity of the material itself leads to a variation in wave amplitude.

Hence, the deviation of the amplitude in percent from the first scan (Fig. 7 a) is exploited for further investigations. The resulting deviation images (compare Eq. 8) reveal fatigue induced changes even in heterogeneous composites. The method is used for detecting delaminations caused by pure axial load. No delaminations were observed within the first $34 \%$ of the lifespan (Fig. 7 b), which was confirmed by visual inspection. However, light axial stripes indicate heterogeneous degradation, which appears to be affected by the initial inhomogeneity of the material. The deviation images after $60 \%, 80 \%, 90 \%$ and $99 \%$ of the lifespan (Fig. 7 c-f, respectively) show initiation and growth of delaminations. 


\subsection{Detection of higher local degradation}

The deviation image of the specimen Tube-30 after $9 \%$ of the lifespan shows considerable changes in amplitude all over the specimen, as depicted in Fig. 8 (left). The binarised image using a threshold of $+18 \%$ (Fig. 8, middle) reveals the areas of the highest changes in the plate wave propagation. Delaminations in these areas were observed by visual inspection after $18 \%$ of the lifespan.

Binarising the deviation image (threshold $+18 \%$ as well) of Tube- 60 after $7 \%$ of the lifespan reveals two stripes at $145^{\circ}$ and $310^{\circ}$ (Fig. 8, right), which correspond to areas of higher crack density. Areas of high crack density, which are expected to result in higher attenuation, on the contrary appear as spots of elevated wave amplitude. The degradation of stiffness due to the incline in crack density results in a local reduction of wave velocity. This leads to a decrease in the difference of acoustic impedance between plate wave and ACU, which is accompanied by higher energy transfer. Furthermore, the energy is trapped locally in low-velocity (damaged) areas due to the wave guiding effect.

\subsection{Analysis of the spot of catastrophic failure initiation}

Separated spots of higher thermal activity caused by cyclic loading usually develop after approximately $90 \%$ of the specimen lifespan, as shown for Tube-60a in Fig. 9 (top).

Two polished aluminium reflectors allow for thermal and optical imaging of $90 \%$ of the tube specimens. Visual inspection of the hot spots revealed high crack density fading into an opaque area.

The deviation image between the ACU area scans at $84.1 \%$ and $95.6 \%$ of the lifespan displays the first evidence of hot spots, as shown for the cooled down Tube-60a in Fig. 
10 (left). The following deviation image (95.6\%-98.7\%) reveals three spots of interest (Fig. 10, centre). Two of them coincide with hot spots detected by thermal imaging. The third spot lies in the small area at the rear side of the specimen, which can not be imaged by the infrared camera. The deviation of the last two ACU plate wave scans at $98.7 \%$ and $99.6 \%$ (Fig. 10, right) clearly indicates the most active hot spot, which appeared to be the area of initiation of catastrophic failure (Fig. 9, bottom).

\section{Conclusions}

Methodologies for non-destructive evaluation of fatigue caused by mechanical loads in wound composite tubes have been proposed. A simple and inexpensive setup, based on a single-sided access configuration of ACU, is suited for remote monitoring of stiffness degradation in composites by measuring the variation in $\mathrm{a}_{0}$-like wave velocity. Internal degradation caused by cyclic loading has been detected by an increase in attenuation of the wave due to scattering on cracks. It has been shown that ACU area scans indicate spots of higher crack density or forming delaminations. For large delaminations not only the size but also the depth of the delamination has been estimated. Being crucial for final failure, hot spots have been monitored by both online thermal imaging and ACU area scans. High speed imaging has revealed that the most obvious spot is likely to be the initiation of catastrophic failure of the tube. The investigation has shown that air-coupled guided waves are a promising instrument for non-contact fatigue monitoring in inhomogeneous composites (infiltrated roving winding), which has been confirmed by stiffness and visual crack density measurements as well as thermal and high speed imaging.

\section{Acknowledgement}


The authors are grateful to the German Research Foundation (DFG) for supporting this work as part of the project PAK267.

\section{References}

[1] Schulte K., Baron C., Neubert N.: Damage development in carbon fibre expoxy laminates: cyclic loading, Composites 1985, pp. 281-285.

[2] Talreja R.: Damage and fatigue in composites - a personal account, Composites Science and Technology 68, 2008, pp. 2585-2591.

[3] Gagel A., Lange D., Schulte K.: On the relation between crack-densities, stiffness degradation and surface temperature distribution of tensile fatigue loaded glassfibre non-crimp-fabric reinforced epoxy, Composites Part A 37, 2006, pp. 222226.

[4] Böhm, R., Hufenbach, W.: Experimentally based strategy for damage analysis of textile reinforced composites under static loading, Composites Science and Technology, 2010.

[5] Victorov I. A.: Rayleigh and Lamb Waves, Plenum Press, New York, 1967.

[6] Mal K., Gorman M. R., and Prosser W. H.: Material characterization of composite laminates using low-frequency plate wave dispersion data, Review of Progress in Quantitative Nondestructive Evaluation 11, 1992, pp. 1451-1458.

[7] Prosser W. H., Gorman M. R.: Plate mode velocities in graphite/epoxy plates, Journal of the Acoustic Society of America 96, 1994, pp. 902-907.

[8] Tang B., Henneke E. G.: Lamb-Wave Monitoring of Axial Stiffness Reduction of Laminated Composite Plates, Material Evaluation, v. 47, 1989, no. 8, pp. 928-934.

[9] Seale M. D., Madaras E. L.: Lamb wave characterization of the effects of longterm thermal-mechanical aging on composite stiffness, Journal of the Acoustic Society of Amercia 106(3), 1999, pp. 1346-1352.

[10] Shih J.-H., Mal A. K., and Vemuri M.: Plate wave characterization of stiffness degradation in composites during fatigue, Research in Nondestructive Evaluation, 10, 1998, pp. 147-162.

[11] Adden S., Pfleiderer K., Solodov I., Horst P., and Busse G.: Characterization of Stiffness degradation caused by fatigue damage in textile composites using circumferential plate acoustic waves, Composite Science and Technology, v. 68, 2008, pp. 1616-1623. 
[12] Rogovsky A. J.: Development and application of ultrasonic dry-contact and aircontact C-scan systems for non-destructive evaluation of aerospace components, Material Evaluation, 49, 1991, pp. 1491-1497.

[13] Castaings M., Cawley P., Farlow R., Hayward G.: Single Sided Inspection of Composite Materials Using Air Coupled Ultrasound, Journal of Nondestructive Evaluation, v. 17, No. 1, 1998, pp. 37-45.

[14] Castaings M., Hosten B.: Ultrasonic guided waves for health monitoring of highpressure composite tanks, NDT\&E International, v. 41, 2008, pp. 648-655.

[15] Solodov I., Döring D.: Ultrasonics for NDE of fiber-composite materials. In: Damage and its evolution in fiber-composite materials: Simulation and nondestructive evaluation, Ed.: G. Busse, B.-H. Kröplin, F.K. Wittel, ISD-Verlag 2006, 17-36.

[16] Haberger C. C., Mann R. W., Baum G. A.: Ultrasonic plate waves in paper, Ultrasonics, 1979, pp. 57-62.

[17] Pavlakovic B., Lowe M., Alleyne D., Cawley P.: DISPERSE: a general purpose program for creating dispersion curves. In: Thompson D, Chimenti D, editors. Review of progress in quantitative NDE, vol. 16. New York: Plenum; 1997, pp. 185-92.

[18] Farnell, G. W.: Types and properties of surface waves. In: Acoustic Surface Waves (Oliner, A. A., ed.). Berlin-Heidelberg-New York: Springer 1978. 


\section{Figures}

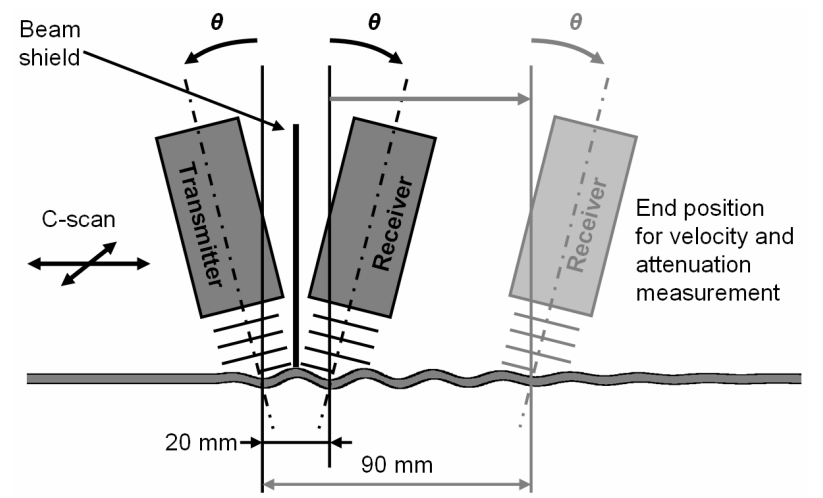

Fig. 1: Air-coupled plate wave configuration (area and velocity/attenuation scan).

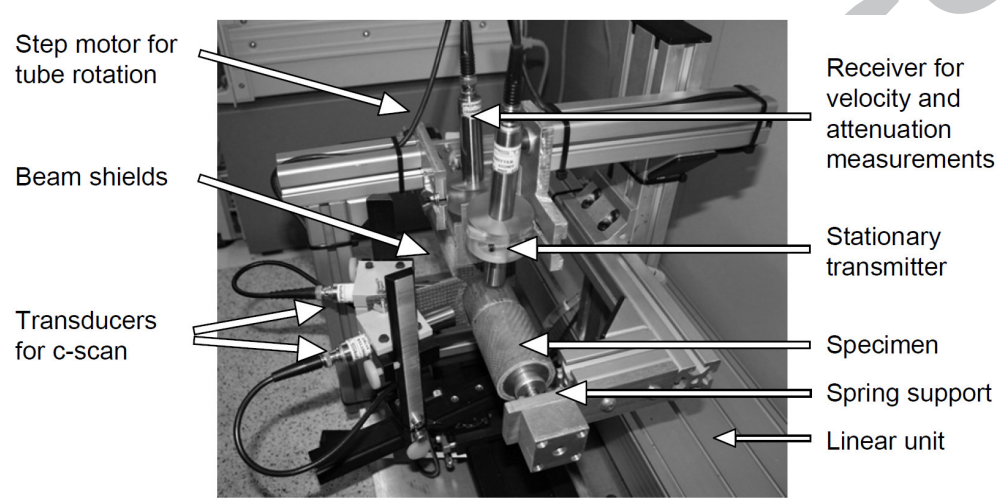

Fig. 2: Scanning apparatus.
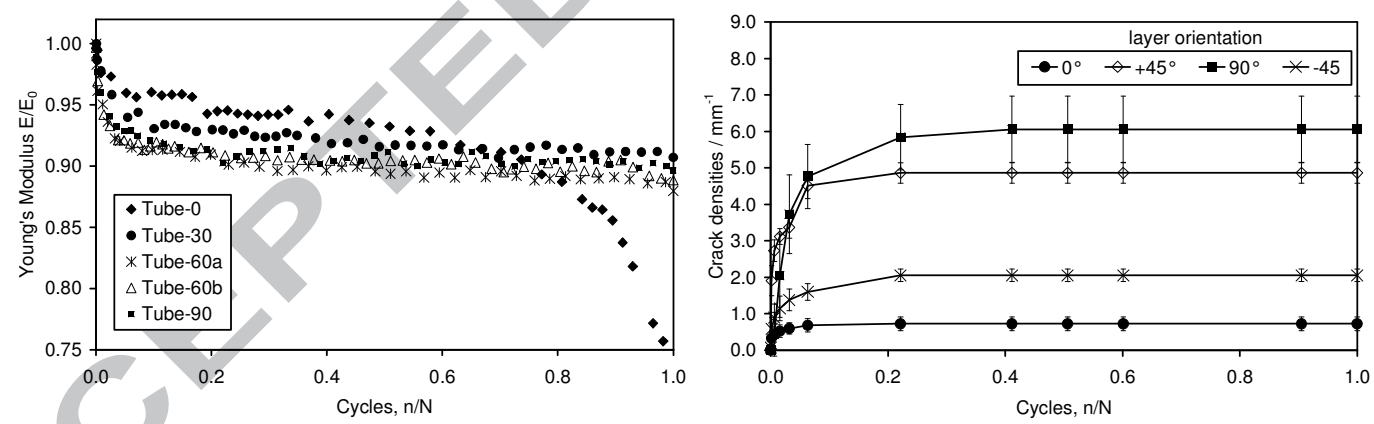

Fig. 3: Young's modulus versus normalized life, specimen names indicate the load ratio $\beta$ (left); crack density in different orientations for Tube-60a (right).
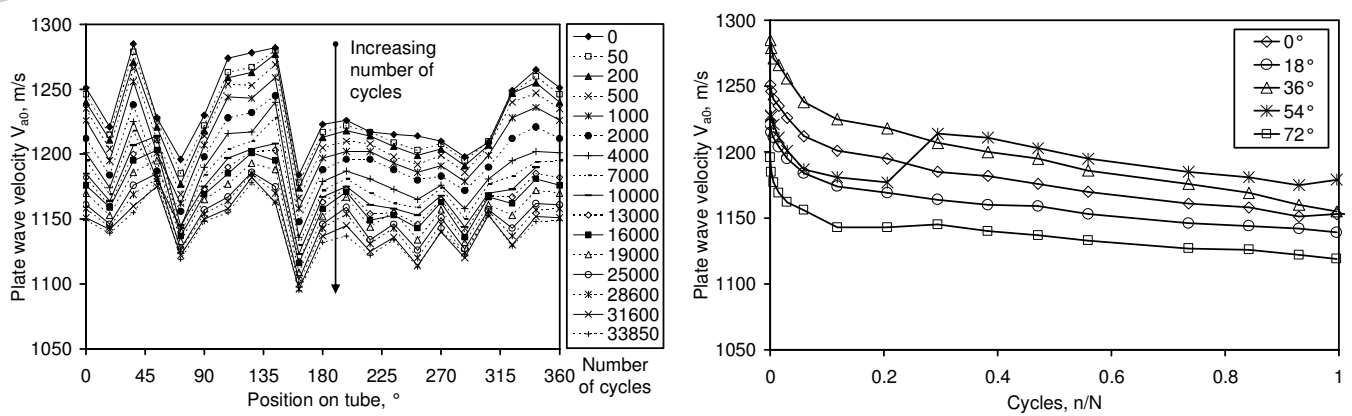

Fig. 4: $\mathrm{a}_{0}$-mode phase velocity along 20 lines at 15 fatigue stages (left) and velocity along 5 lines throughout lifespan (right) of Tube-60a. 


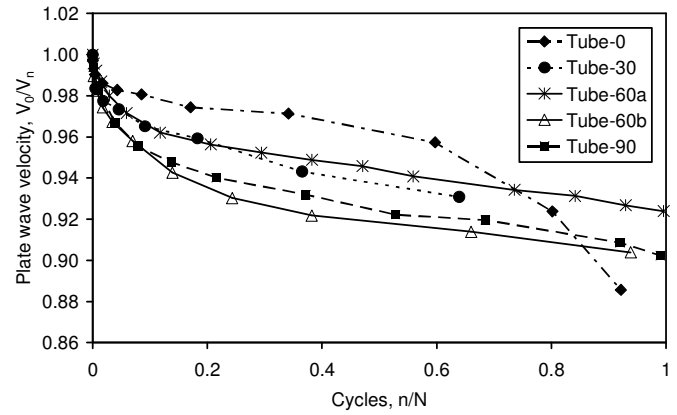

Fig. 5: Decline in phase velocity in 5 specimens over lifespan.
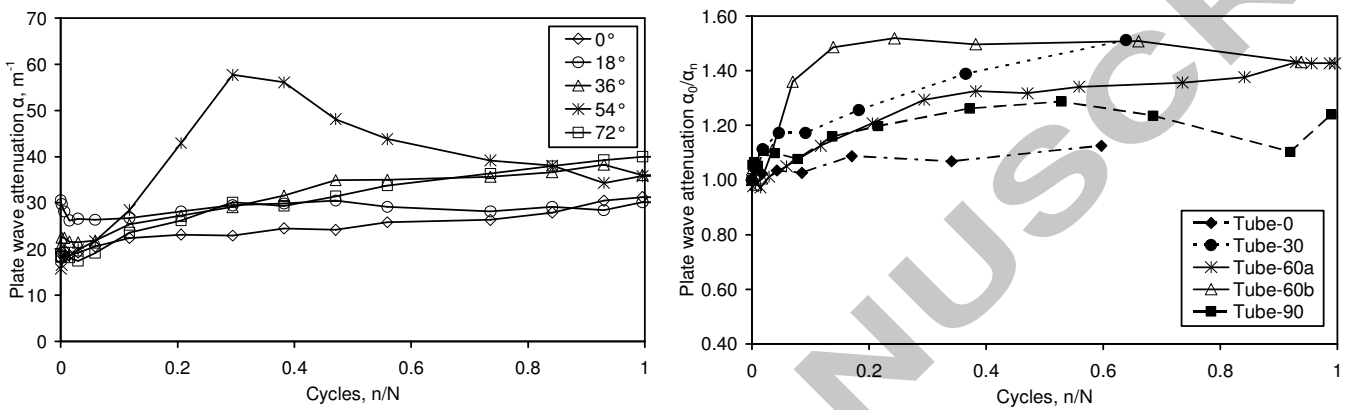

Fig. 6: Plate wave attenuation along 5 lines throughout lifespan for Tube-60a (left); averaged increase in plate wave attenuation due to fatigue for 5 specimens (right).

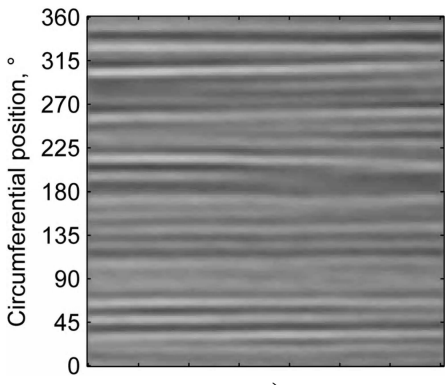

a)

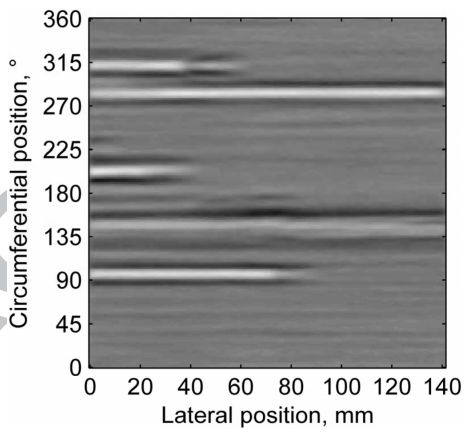

d)

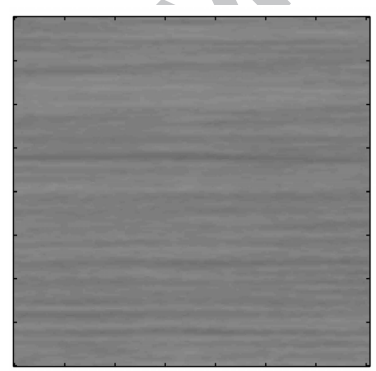

b)

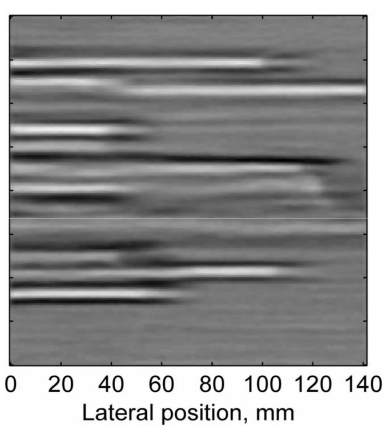

e)

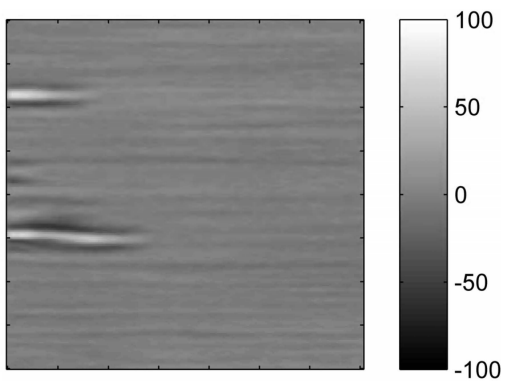

c)

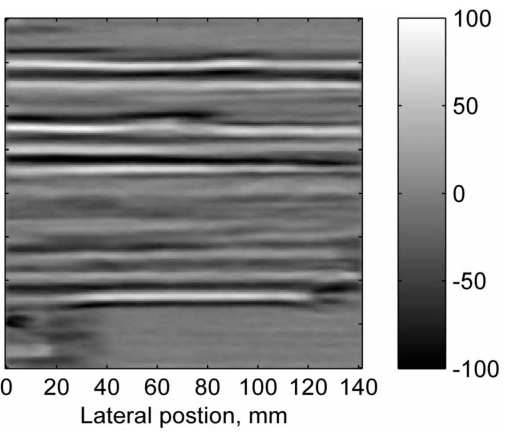

f)

Fig. 7: Plate wave scan of intact specimen a); forming of delaminations (34\%, $60 \%$, $80 \%, 90 \%, 99 \%$ of the lifespan) monitored by subtraction of grey values b-f), Tube- 0 . 

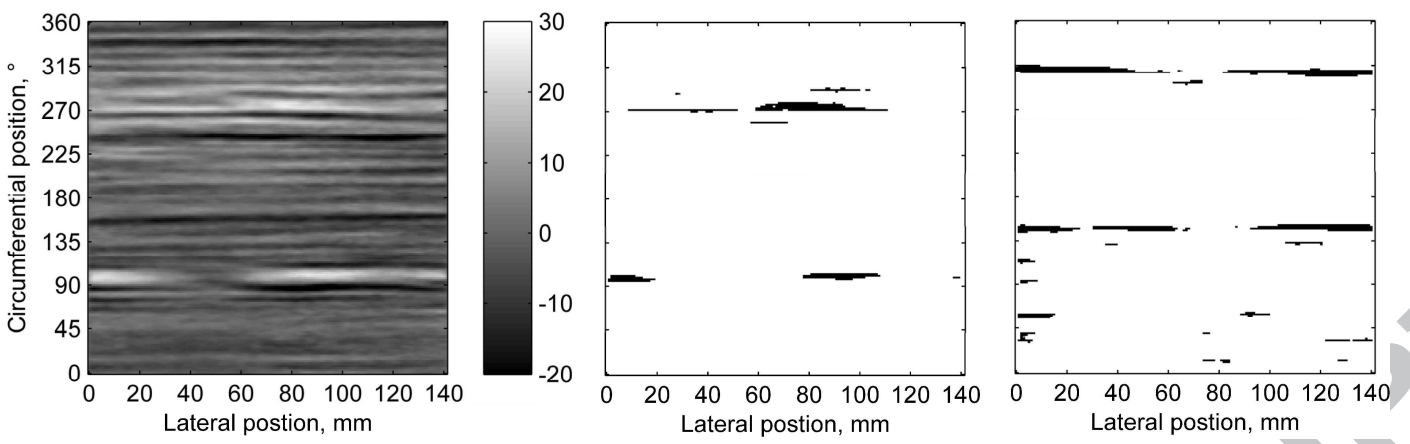

Fig. 8: Deviation image of Tube-30 at $9 \%$ of lifespan (left), same scan binarised at a threshold of $18 \%$ (centre), and binarised deviation image of Tube-60 at $7 \%$ of the lifespan (right).

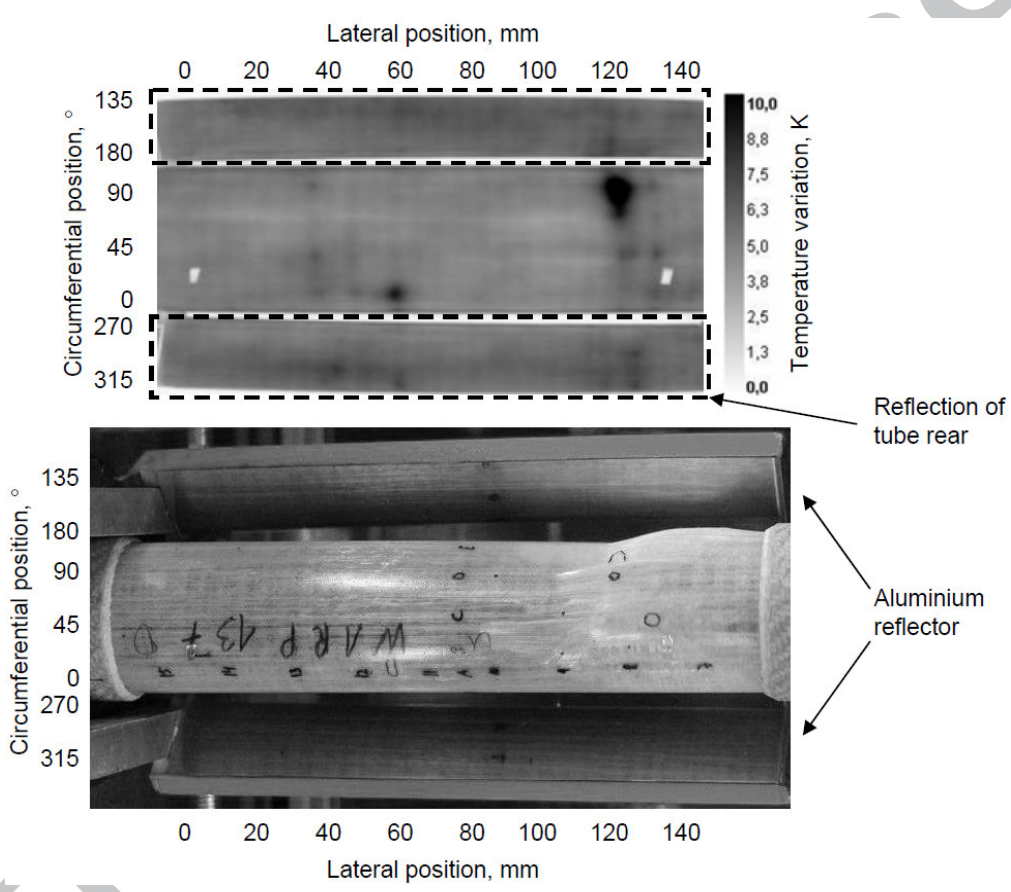

Fig. 9: Infrared image at $99.6 \%$ of the lifespan of Tube-60a (top); optical high-speed image at failure initiation of Tube-60a (bottom).
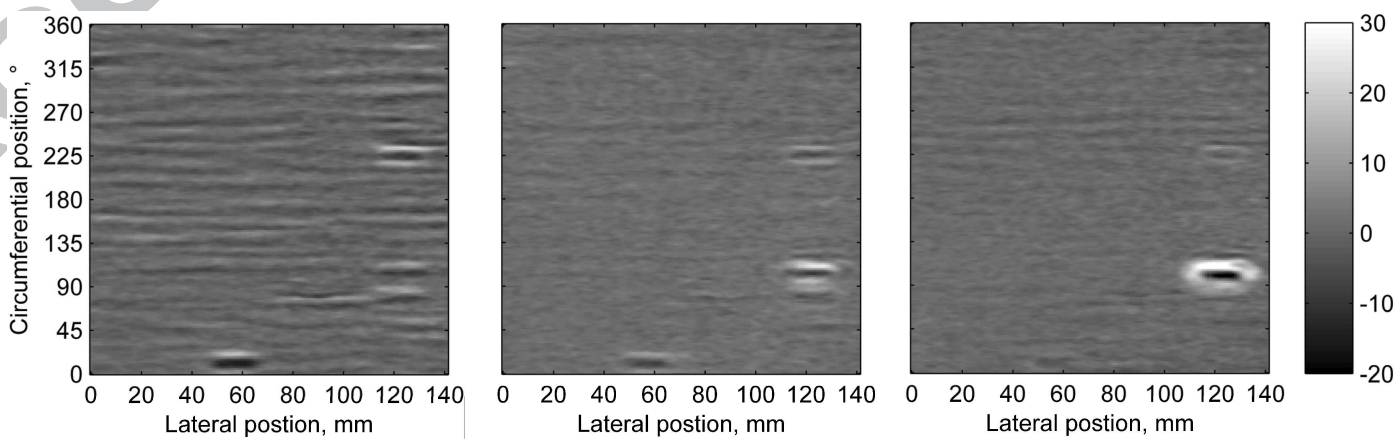

Fig. 10: Deviation of ACU scans between different fatigue stages at the end of the lifespan of Tube-60a (from left to right: 84.1-95.6\%, 95.6-98.7\%, and 98.7-99.65\%). 


\section{Tables}

Table 1: Mechanical parameters of the materials

\begin{tabular}{|c|c|}
\hline \multicolumn{2}{|c|}{ Fibre OC111A } \\
\hline Young`s-Modulus & $80.7 \mathrm{GPa}$ \\
\hline Tensile strength & $2.56 \mathrm{GPa}$ \\
\hline Density & $2.58 \mathrm{~g} / \mathrm{cm}^{3}$ \\
\hline \multicolumn{2}{|c|}{ Resin/hardener L135i/ H137i } \\
\hline Tensile modulus & $3.2-3.5 \mathrm{GPa}$ \\
\hline Tensile strength & $70-80 \mathrm{MPa}$ \\
\hline Compression strength & $120-140 \mathrm{MPa}$ \\
\hline Elongation at rupture & $5.0-6.5 \%$ \\
\hline Density & $1.18-1.20 \mathrm{~g} / \mathrm{cm}^{3}$ \\
\hline Glass transition temperature & $90^{\circ} \mathrm{C}$ \\
\hline
\end{tabular}

Table 2: Loading programme, fibre-volume ratios and lifespan for all specimen

\begin{tabular}{|l|c|c|c|c|c|c|}
\hline Specimen & $\beta /{ }^{\circ}$ & FVR / \% & $\sigma / \mathrm{MPa}$ & $\tau / \mathrm{MPa}$ & $\begin{array}{c}\text { Cyclic load over } \\
\text { static failure load / \% }\end{array}$ & $\begin{array}{c}\text { lifespan / } \\
\text { cycles }\end{array}$ \\
\hline Tube-90 & 90 & 48.8 & 0 & 69 & 43 & 51094 \\
\hline Tube-60a & 60 & 50.7 & 43 & 75 & 43 & 33987 \\
\hline Tube-60b & 60 & 51.4 & 44 & 76 & 43 & 28773 \\
\hline Tube-30 & 30 & 50.5 & 116 & 67 & 41 & 10948 \\
\hline Tube-0 & 0 & 51.1 & 194 & 0 & 33 & 11722 \\
\hline
\end{tabular}

